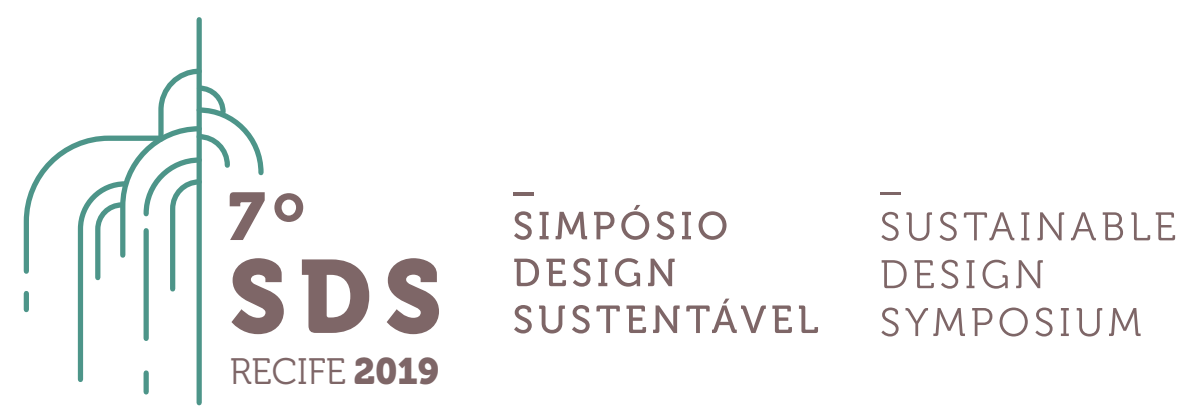

\title{
Perspectivas de design sobre reúso de embalagens de consumo no ambiente doméstico
}

\author{
Caio Dutra Profirio de Souza ${ }^{1, a}$ e Cyntia Santos Malaguti de Sousa ${ }^{1, b}$ \\ ${ }^{1}$ Universidade de São Paulo (USP), Faculdade de Arquitetura e Urbanismo (FAU), São Paulo - SP, Brasil \\ a Mestrando, Programa de Pós-Graduação em Design, caiodutra@usp.br \\ brofessora Doutora, cyntiamalaguti@usp.br
}

Resumo. Devido ao seu caráter programado de uso único e consequente descarte acelerado, embalagens de consumo constituem grande parte dos resíduos sólidos domésticos. Como tentativa de reduzir impactos ambientais, algumas alternativas de prolongar a vida útil desses artefatos são ocasionalmente observadas, tais como embalagens refil ou retornáveis. Todavia, além de exemplos esparsos, em muitos casos seriam estratégias meramente mercadológicas e não soluções centradas no usuário. Por outro lado, é possível perceber, muitas vezes, que as pessoas atribuem novas funções a esses artefatos, como por exemplo para solucionar necessidades domésticas. Deste modo, considera-se que deveria haver mais investigações sobre como embalagens de consumo poderiam proporcionar experiências positivas mais complexas e duradouras para além de suas funções primárias, tendo como ponto central de projeto não apenas questões ambientais, mas também o usuário e suas carências. Isto posto, este artigo coloca em questão como o design poderia estimular a reutilização doméstica de embalagens de consumo, indagação que levou a uma Revisão Sistemática da Literatura (RSL) em bases de dados científicas brasileiras, abrangendo artigos, dissertações e teses, com o intuito de mapear pesquisas que forneçam considerações sobre o assunto. Os resultados realçam que há poucos estudos nacionais que abordam essa questão e, em geral, apenas sugerem o reaproveitamento de embalagens pelo usuário como uma estratégia que pode ser considerada durante o processo projetual. Em nenhuma das pesquisas, no entanto, o reúso é vislumbrado como conceito capaz de orientar todo o planejamento de algumas embalagens de consumo. Deste modo, evidencia-se uma lacuna que pode fomentar futuras investigações.

Palavras-chave. Design de embalagem; design para reúso; resíduos domésticos. 


\section{Introdução}

Embalagens de consumo são, ocasionalmente, observadas em situações de reúso em diferentes contextos em residências brasileiras.

Simples mudanças de sentido, tais como latas de biscoitos que passam a acondicionar agulhas e linhas de costura, potes de margarina que se tornam saboneteiras, latas de extrato de tomate que se transformam em porta-escovas de dentes e caixas de eletrodomésticos recém-adquiridos que passam a abrigar brinquedos, são alguns dos exemplos de embalagens que, após cumprirem seu propósito inicial, expressam novas possibilidades de uso no ambiente doméstico (geralmente não previstas no projeto de design) e, por intermédio de seus usuários, recebem uma segunda vida.

Nota-se, em muitos casos, que não há modificações significativas nas embalagens para o reaproveitamento doméstico, já que muitas mantêm suas características de aquisição (tais como estrutura, grafismos e, em alguns casos, rótulos), mesmo estes deixando evidente o propósito inicial, já cumprido pelo artefato, de embalar produtos já consumidos. A ressignificação da função de embalagens dentro do lar, portanto, não implicaria, necessariamente, na sua transformação formal, uma vez que elas são, muitas vezes, reutilizadas da maneira que foram projetadas.

Considera-se que, por serem planejadas para uso efêmero e se tratarem de produto de demanda secundária (portanto mais sujeitas a restrições de custos no projeto e produção), há pouca reflexão sobre como embalagens podem fornecer experiências positivas mais complexas e duradouras além de suas funções primárias, de modo que beneficiem usuários e tenham o menor impacto ambiental possível. Este impacto associa-se, entre outros fatores, ao fato de que, do ponto de vista de sua materialidade, a vida da maioria das embalagens se estende por período muito maior do que o planejado. Esta característica contraditória possibilita que tais artefatos sejam situados no mesmo patamar que outros considerados "duráveis", permanecendo por mais tempo em uso, exercendo outras funções, mediante experimentações e apropriações pós-consumo - lado experimental que pode ser discutido, em nível mais abstrato, como uma aproximação à metodologia de projeto de design.

Portanto, tendo em vista as centenas de embalagens com as quais entramos em contato todos os dias, torna-se essencial problematizar seu papel na vida cotidiana, refletindo sobre como seus atributos positivos podem ser potencializados e aprimorados na etapa de projeto, em que "projetar para reúso" poderia ser um dos possíveis caminhos de inovação pelo design rumo à sustentabilidade. Isto posto, coloca-se em questão neste artigo como estimular o reúso de embalagens de consumo no ambiente doméstico, segundo perspectivas de projeto de design.

O objetivo principal é expor considerações sobre este questionamento com base em uma Revisão Sistemática da Literatura (RSL), em que se buscou identificar autores e estudos brasileiros que tangenciam esta temática, com o intuito de verificar o estado da arte do objeto em evidência.

Almeja-se, com os resultados obtidos, estimular futuros estudos que dialoguem com este tema, bem como contribuir para a prática de áreas envolvidas no projeto de embalagens.

\section{Embalagem, reúso e conservação ambiental}

Single-use ("uso único") foi eleita "palavra do ano" de 2018 pelo dicionário britânico Collins, como uma maneira de sinalizar os problemas ambientais decorrentes de artefatos produzidos para serem utilizados apenas uma vez. Segundo site oficial do dicionário, o uso desta palavra aumentou em quatro vezes desde 2013, gerando grande repercussão na mídia e estimulando reflexões públicas a respeito do assunto. 
De acordo com o último "Panorama dos Resíduos Sólidos no Brasil", divulgado pela ABRELPE (2018), a geração de Resíduos Sólidos Urbanos (RSU) no país atingiu, em 2017, um total de 214.868 toneladas por dia, dos quais quase a metade é proveniente da região Sudeste (105.794 toneladas). Desses valores, estima-se que quase $1 / 3$ é composta por embalagens (Ministério do Meio Ambiente, online, 2019), o que evidencia a importância de se colocar este tipo de artefato e sua prática projetual em questão.

Segundo Jedlička (2009), o ideal rumo à sustentabilidade seria projetar produtos sem a necessidade de invólucros. Embora considerando-se o caráter talvez utópico deste ideal, o desenvolvimento de embalagens reutilizáveis voltadas ao atendimento de necessidades domésticas, pode ser uma interessante alternativa nesta direção, aparentemente ainda pouco investigada no campo do design. Em pesquisas exploratórias anteriores à esta revisão, foram detectados poucos estudos diretamente associados ao reúso de embalagens de consumo, principalmente no que diz respeito ao reaproveitamento destes artefatos no ambiente doméstico e as implicações deste fenômeno na conservação ambiental.

Até o momento, o estudo mais relevante identificado foi o de Fisher e Shipton (2010), em que os autores sugerem que o reúso de embalagens de consumo é geralmente ignorado, tanto em termos de investigação quanto de projeto, e por esse motivo conduziram uma pesquisa para entender como se dão as transformações de função e valor desses artefatos em residências no Reino Unido. Para tanto, os autores desenvolveram uma investigação exploratória com a intenção de catalogar algumas das manifestações do reaproveitamento e identificar os principais contextos em que ocorrem, por meio de entrevistas semiestruturadas com usuários selecionados e observações diretas em moradias. Frente às especificidades de nosso país, acredita-se que haveria uma lacuna de um estudo similar no Brasil.

Outra pesquisa pertinente já mapeada é a dissertação de Gomes (2011), que parte de considerações e conceitos da análise de Fisher e Shipton (2010) para abordar o reúso de embalagens como uma das diversas possibilidades de reaproveitamento de artefatos. Nesta análise, discute-se a reutilização associada aos projetos de design de maneira mais ampla, contemplando novos usos tanto para artefatos quanto para materiais provenientes destes em projetos de arquitetura, de mobiliário e na indústria têxtil, entre outros, além de apresentar alguns exemplos dessas manifestações. O autor enfatiza que "apesar de o tópico não ser novo [...], é actual e de grande interesse, não só pela sua vertente ecológica mas também pelo lado experimental e criativo associado à reutilização de objectos fora das funções para as quais foram originalmente desenhados." (GOMES, 2011, p. 2).

Shedroff (2009) avalia que muitos artefatos poderiam expressar alternativas de reúso se os designers as incorporassem ao processo de desenvolvimento. Fisher e Shipton (2010) evidenciam, entretanto, que projetar possíveis formas de reaproveitamento requer cautela, já que, conforme constataram em seu estudo a respeito das embalagens, essas possibilidades não podem ser limitantes aos usuários, uma vez que isso seria ignorar as principais motivações para a reutilização: inventividade, criatividade e expressão de identidade. Para os autores, projetos que apresentam potencial para múltiplos reúsos podem resultar em uma frequência maior de reaproveitamento.

Em relação a obras brasileiras sobre projeto de embalagem preliminarmente analisadas, temos o pioneiro "Manual para planejamento de embalagens" (BERGMILLER et al., 1976), que reúne conceitos e um método para auxiliar no desenvolvimento de embalagens no contexto nacional da época. Os autores abordam brevemente o reúso de embalagens ao apontarem para a necessidade de se pensar nesta dimensão em um "checklist de controle projetual". O reúso no ambiente doméstico, especificamente, é mencionado em um exemplo de projeto de embalagem para café solúvel, destacando o vidro como um dos materiais mais viáveis para este tipo 
de projeto, devido às características deste material "[...] o atrativo maior em sua reutilização para fins domésticos" (BERGMILLER et al, 1976, p. 83).

Negrão e Camargo (2008), por sua vez, reproduzem em sua obra o método de Lincoln Seragini para desenvolvimento de embalagens. A etapa de "planejamento preliminar", também consiste em um checklist, do qual destaca-se o último item: "11. A embalagem é reutilizável, reciclável ou retornável?" (NEGRÃO; CAMARGO, 2008, p. 139). Considerando-se o espaço temporal entre essas duas obras e apesar de apresentarem abordagens pontuais e genéricas a respeito do reaproveitamento de embalagens, é interessante notar que em ambas este aspecto é considerado como merecedor de atenção no processo projetual.

Ainda no texto de Negrão e Camargo (2008), os autores comentam sobre o reúso ser um dos conceitos que compõe os clássicos três "erres" na hierarquia de resíduos (reduzir, reutilizar e reciclar), e mencionam que é possível "[...] aplicar este princípio desenvolvendo embalagens que não terão descarte imediato e poderão ser reutilizadas pelo usuário, como potes, copos de vidro etc." (p. 284-285). A respeito dos três "erres", Fisher e Shipton (2010) acrescentam que embora o reúso seja o segundo, sua importância ainda não tem sido enfatizada, em termos de investimento, conscientização e compreensão, constatação que, associada ao panorama dos resíduos sólidos apresentado anteriormente, demonstra a pertinência desta investigação.

\section{Revisão Sistemática da Literatura (RSL)}

A Revisão Sistemática da Literatura (RSL), conforme método Cochrane (HIGGINS; GREEN, 2011), consiste em uma "[..] pesquisa bibliográfica que objetiva um processo de levantamento de dados, onde são exigidas revisões rigorosas de publicações acadêmicas que permitam mapear evidências sobre determinado tema na área pretendida" (OBREGON, 2017, p. 13). Para tanto, elabora-se uma pergunta claramente definida que norteará toda a investigação e um protocolo de pesquisa com os critérios de busca, seleção e exclusão de estudos identificados, com o intuito de que a revisão possa ser facilmente replicada, ampliada e revista.

A seguir, apresenta-se a questão da pesquisa, o protocolo com os parâmetros de investigação, considerações sobre as buscas realizadas nas bases de dados, descrição dos estudos incluídos na revisão e uma síntese dos resultados obtidos, seguida de breves considerações finais.

\subsection{Questão da pesquisa}

Salienta-se que a questão desta Revisão Sistemática da Literatura (RSL) foi escolhida a partir de um conjunto de indagações exploratórias de uma pesquisa de mestrado em desenvolvimento. Esta foi eleita por almejar identificar perspectivas essencialmente de projeto, haja vista que tais informações são consideradas como imprescindíveis para que se possa discutir demais abordagens possíveis em relação a este tema e que já foram consideradas como merecedoras de atenção, tais como: percepções de usuários, cultura material, consumo e valores, projeto para durabilidade, design participativo e vínculos afetivos.

Questão da pesquisa: Como estimular o reúso de embalagens de consumo no ambiente doméstico, segundo perspectivas de projeto de design?

\subsection{Protocolo de pesquisa}

O protocolo de pesquisa (Quadro 1) apresenta os critérios de busca adotados nesta revisão, tais como: bases de dados definidas, tipos de documentos pesquisados, período de publicação, palavras-chave utilizadas e critérios para inclusão e exclusão de estudos identificados. 
Quadro 1 - Protocolo de pesquisa da Revisão Sistemática da Literatura

\begin{tabular}{ll}
\hline Base de dados & SciELO, Biblioteca Digital Brasileira de Teses e Dissertações (BDTD) e CAPES \\
\hline Tipos de documentos & Artigos, dissertações e teses \\
\hline Período & A partir de 2000 \\
\hline Idioma & Português \\
\hline Localização dos termos & Título, resumo, assunto e/ou palavra-chave \\
\hline Áreas temáticas & Ciências sociais aplicadas, engenharias e multidisciplinar \\
\hline Palavras-chave & $\begin{array}{l}\text { 1. embalagem } \\
\text { 2. design }\end{array}$ \\
$\begin{array}{l}\text { 3. reúso OR reutilização OR reaproveitamento } \\
\text { 4. sustentabilidade }\end{array}$ \\
\begin{tabular}{l} 
5. “ambiente doméstico" OR residência OR moradia \\
\hline Critérios de inclusão
\end{tabular} \\
$\begin{array}{l}\text { Investigações que tangenciam a temática do reúso de embalagens de consumo } \\
\text { no ambiente doméstico, segundo perspectivas de projeto de design. }\end{array}$ \\
\hline Critérios de exclusão & $\begin{array}{l}\text { Investigações que não contribuam com dados e reflexões relevantes sobre o } \\
\text { de projeto de design, bem como trabalhos duplicados. }\end{array}$ \\
\hline
\end{tabular}

Fonte: os autores

\subsection{Pesquisas nas bases de dados}

Após elaboração do protocolo de pesquisa, foram definidas 6 associações de palavraschave para busca nas bases de dados, detalhadas no Quadro 2 abaixo:

Quadro 2 - Associações de palavras-chave e ordem de busca nas bases de dados

\begin{tabular}{ll}
\hline $\mathbf{N o}$ & Associação de palavras-chave \\
\hline $\mathbf{1}$ & (embalagem) AND (design) \\
$\mathbf{2}$ & (embalagem) AND (reúso OR reutilização OR reaproveitamento) \\
$\mathbf{3}$ & (embalagem) AND (sustentabilidade) \\
$\mathbf{4}$ & (embalagem) AND (“ambiente doméstico” OR residência OR moradia) \\
$\mathbf{5}$ & (design) AND (reúso OR reutilização OR reaproveitamento) \\
$\mathbf{6}$ & (reúso OR reutilização OR reaproveitamento) AND (“ambiente doméstico” OR residência OR moradia) \\
\hline
\end{tabular}

Fonte: os autores

As buscas, realizadas entre os dias 15 e 20 de março de 2019, seguiram a ordem de associações de palavras-chave apresentadas na coluna "№", do Quadro 2, e foram realizadas primeiro na base de dados da SciELO, em seguida, na base da Biblioteca Digital Brasileira de Teses e Dissertações (BDTD), e por último, na base de dados da CAPES, mediante particularidades de busca em cada uma, conforme Quadro 3. 
Quadro 3 - Especificidades de busca nas bases de dados
SciELO
Busca avançada das associações de palavras-chave em "todos os índices".
BDTD Busca avançada das associações de palavras-chave em "todos os campos" e com "todos os termos".
CAPES Busca avançada, em "assunto", das associações de palavras-chave em "qualquer" e "contém".

\section{Fonte: os autores}

A seleção inicial dos estudos se deu a partir da leitura dos títulos e resumos de todos os resultados identificados nas buscas (totalizando 1.237 publicações), procurando-se estabelecer relações com a questão da pesquisa. Deste modo, foram selecionados na medida em que apareciam pela primeira vez, tanto em relação à ordem de pesquisa de associações de palavraschaves (Quadro 2), quanto em relação à ordem de busca nas bases de dados. Isto posto, a medida em que possivelmente apareciam novamente eram ignoradas.

A Figura 1 apresenta a relação de estudos identificados ("I") e selecionados ("S") em cada associação de palavras-chave e em cada base de dados.

Figura 1 - Relação dos estudos identificados ("I") e selecionados ("S")

a partir das associações de palavras-chave nas bases de dados

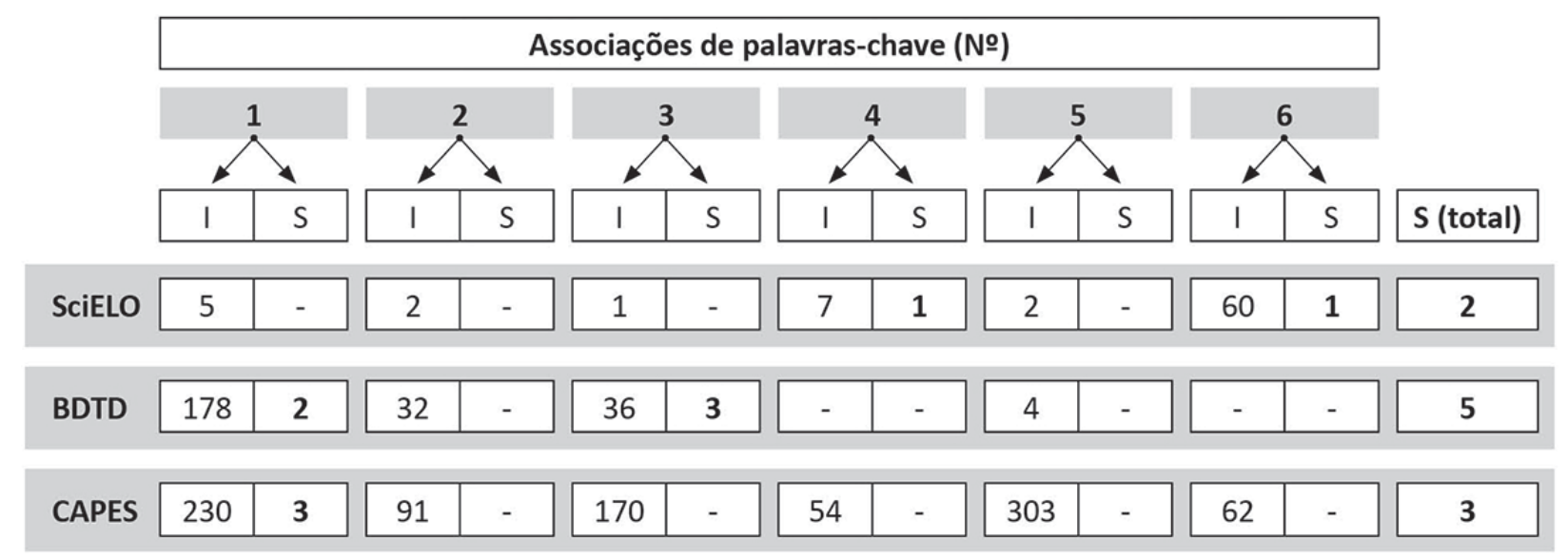

Fonte: os autores

Ressalta-se que, embora algumas buscas na base da CAPES tenham identificado considerável número de itens, grande parte não apresentava correspondências com a temática da investigação. Optou-se, entretanto, por não aplicar outros filtros, além dos estabelecidos no protocolo de pesquisa, por considerar-se que seria importante um mapeamento mais amplo das publicações com as palavras-chave definidas.

Os 10 estudos selecionados foram submetidos a leitura mais atenta da introdução, procedimentos metodológicos e resultados. A partir disto, 6 estudos foram excluídos e 4 incluídos na revisão (Figura 2), sendo que dos incluídos, três foram resultados de buscas na base da Biblioteca Digital Brasileira de Teses e Dissertações (BDTD) e um na base da SciELO. 
Figura 2 - Relação de estudos excluídos e incluídos na revisão

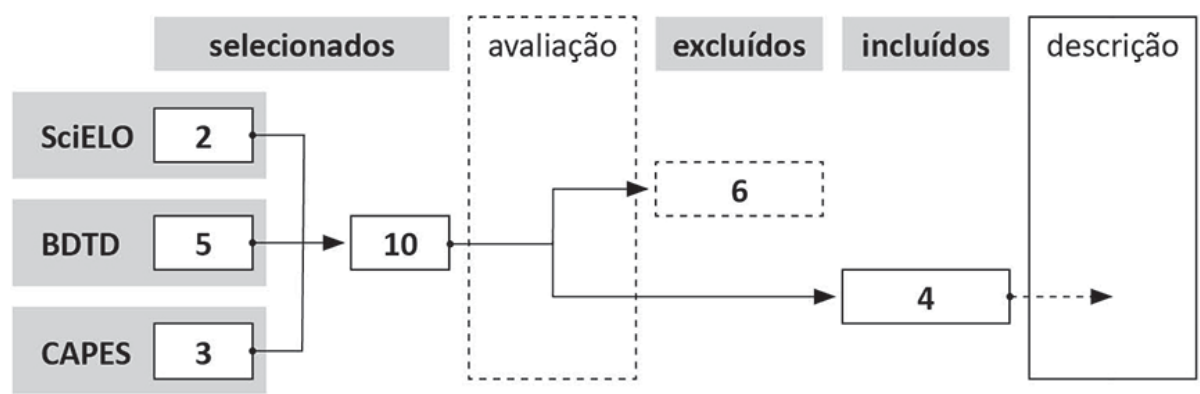

Fonte: os autores

Dentre as principais motivações para exclusão, destaca-se a fuga do enfoque da questão desta pesquisa, a apresentação de perspectivas diversificadas (tais como de consumidores e de mercado) e não de projeto, ou ainda, a presença de poucos dados e reflexões relevantes à resposta do problema, conforme critérios de inclusão e exclusão expostos no protocolo de pesquisa (Quadro 1). Ademais, três estudos (dois artigos e uma dissertação de mestrado) de um mesmo autor haviam sido selecionados, mas apenas a dissertação foi incluída na revisão, uma vez que as discussões e resultados dos dois artigos eram parte do conteúdo da dissertação.

O Quadro 4 abaixo apresenta a relação dos estudos que serão descritos no tópico seguinte.

Quadro 4 - Relação dos estudos incluídos na revisão

a BUCCI, D. Z. Processo de desenvolvimento de produto-embalagem: uma proposta orientada à sustentabilidade. Tese (Doutorado) - Centro Tecnológico, Universidade Federal de Santa Catarina, Florianópolis, 2010.

b CAPELINI, M. Potencialidade e aplicação da prevenção de resíduos de embalagens: abordagem sobre o projeto do produto e o consumo. 2007. Tese (Doutorado) - Escola de Engenharia de São Carlos, Universidade de São Paulo, São Carlos, 2007.

c GONCALVES-DIAS, S. L. F. Há vida após a morte: um (re)pensar estratégico para o fim da vida das embalagens. Gestão \& Produção, São Carlos, v. 13, n. 3, p. 463-474, Dez. 2006.

d PEREIRA, P. Z. Proposição de metodologia para o design de embalagem orientada à sustentabilidade. Dissertação (Mestrado) - Escola de Engenharia, Universidade Federal do Rio Grande do Sul, Porto Alegre, 2012.

Fonte: os autores

\subsection{Descrição dos estudos}

Em seguimento, apresenta-se as contribuições identificadas, em cada um dos 4 estudos incluídos na revisão (Quadro 4), para a temática desta pesquisa.

\subsubsection{Estudo " $a$ "}

Ao constatar que grande parte dos artefatos e suas embalagens são desenvolvidos em processos projetuais independentes, Bucci (2010) coloca em questão como integrar as duas dimensões de planejamento, a do produto e a de sua embalagem, tendo como ponto central questões de sustentabilidade, com o intuito de reduzir os impactos ambientais do conjunto final.

Segundo a autora, o planejamento da embalagem no Processo de Desenvolvimento do Produto (PDP) é geralmente visto como a última etapa de projeto, o que prejudica o desempenho final de ambos, procedimento agravado pela pouca interação entre as equipes que os desenvolvem. O curto tempo de uso das embalagens é indicado como um dos fatores 
determinantes para se pensar em estratégias de projeto integrativas com o produto que irão acondicionar, uma vez que os impactos ambientais gerados pelas embalagens são grandes e que são escassas as abordagens que visam diminuí-los ainda na fase de planejamento, o que incluiria embalagens retornáveis ou reutilizáveis. O reúso de embalagens é mencionado algumas vezes como uma alternativa, entretanto, com um caráter apenas indicativo, em que se aponta para a possibilidade ou para a necessidade de considerar esta dimensão durante o desenvolvimento do produto-embalagem. Além disso, grande parte dessas menções é pela perspectiva de reaproveitamento das embalagens pelas indústrias, e não pelo usuário.

Todavia, a principal contribuição deste texto para a questão desta pesquisa encontra-se no processo de desenvolvimento proposto pela pesquisadora, denominado de PDPES (Processo de Desenvolvimento de Produto-Embalagem Sustentável), elaborado a partir da revisão do referencial teórico, pesquisas de campo em empresas e entrevistas com especialistas. Esta pode ser uma interessante ferramenta e ponto de partida para se pensar em uma metodologia específica de "projeto para reúso" que englobe embalagem e produto, uma vez que se trata de uma abordagem sistêmica centrada em aspectos de conservação ambiental e pode contribuir para diferentes dimensões do produto-embalagem, tais como aspectos ergonômicos e funcionais, melhor aproveitamento de materiais e recursos, redução de custos de produção, diminuição de resíduos e agressões ao meio ambiente. Ademais, esta metodologia pode subsidiar discussões mais profundas sobre o caráter da embalagem como produto em si, e as oportunidades de o usuário vê-la desta maneira, colocando em questão o ponto de vista de Mestriner (apud BUCCl, 2010, p. 67), a respeito da classificação da embalagem em relação aos demais produtos industriais, de que esta "[...] não é um produto final em si, mas um componente de um produto que ela contém e que, este sim, é adquirido e consumido pelo consumidor. A embalagem é meio e não fim", ou considerado de demanda secundária, como comentado no início deste artigo.

\subsubsection{Estudo " $b$ "}

Esta tese parte do ponto de vista de que a maneira mais efetiva para lidar com resíduos é prevenindo-os na etapa de projeto. Portanto, propõe-se a investigar algumas das possibilidades para se reduzir resíduos de embalagens com enfoque no processo projetual e em questões de consumo e de legislações ambientais. O intuito é apresentar um panorama sobre a situação brasileira (no contexto da publicação da pesquisa) quanto ao desenvolvimento de embalagens com vistas a diminuição da geração de resíduos. Salienta-se que, devido à data de publicação desta tese (2007), grande parte dos assuntos abordados já se encontram em outro patamar de discussão, dentre os quais destaca-se a Política Nacional de Resíduos Sólidos e aspectos de consumo no Brasil.

As principais relações com a questão desta pesquisa se dão na medida em que a autora faz algumas menções ao "projeto para reúso". Segundo Capelini (2007), esta abordagem seria uma das estratégias para extensão de vida do produto-embalagem, com uso para a mesma função ou outras distintas, e menciona como exemplo os copos de vidro de requeijão que podem ser reaproveitados como copos de uso diário. Sugere, contudo, que é necessário inserir requisitos específicos quando se espera menor impacto ambiental com este tipo de projeto. De acordo com a pesquisadora:

\footnotetext{
"No projeto para reuso, a resistência da embalagem e sua durabilidade são fatores muito importantes. Sousa (2000) atenta para a necessidade de se evitar superfícies rugosas internamente, facilitando assim a retirada completa do produto e limpeza da embalagem destinada ao reuso. A autora lembra também que a forma da embalagem é muito importante nesse sentido." (CAPELINI, 2007, p. 137).
} 
A autora também apresenta um quadro, adaptado de Manzini e Vezzoli (2002), com algumas indicações para otimização de vida dos produtos, dentre as quais se encontra uma sobre reutilização, com as seguintes considerações:

Quadro 5 - Indicações para otimização de vida dos produtos: facilitar a reutilização

\section{Facilitar a reutilização:}

Incrementar a resistência das partes mais sujeitas a avarias e rupturas

Predispor o acesso para facilitar a remoção das partes e componentes que podem ser reutilizados

Projetar partes e componentes intercambiáveis, modulares e padronizados

Projetar a reutilização de partes auxiliares

Projetar possibilidade de recarga e/ou reutilização das embalagens

Projetar prevendo um segundo uso

Fonte: adaptado de CAPELINI, 2007, p. 128.

Capelini (2007) conclui enfatizando que as embalagens, como produtos em si, também devem ser projetadas com o mesmo rigor de outros artefatos para gerar o menor impacto ambiental possível, o que demanda dos profissionais envolvidos em seu desenvolvimento constante atualização quanto aos processos, materiais e normas relacionados a este tipo de projeto e constante busca por novas e melhores soluções.

\subsubsection{Estudo "c"}

Este artigo parte da análise do processo de reciclagem de embalagens feitas de PET (Politereftalato de Etileno) no Brasil para introduzir um panorama dos aspectos associados à gestão dos resíduos de embalagens, principalmente no que diz respeito à logística reversa e ao ciclo de vida, com o intuito de expor algumas das variáveis que influenciam de maneira positiva ou negativa a etapa de pós-consumo de embalagens, considerando-se o cenário nacional da época.

Assim como destacado na descrição do estudo "b", grande parte dos assuntos tratados neste texto, tais como responsabilidade estendida do produtor, já avançaram em termos de pesquisa, implementação e reflexão, devido à data de sua publicação (2006). Entretanto, evidenciam-se dois apontamentos que se mostraram relevantes para esta investigação. Em primeiro lugar, encontra-se as menções que a autora faz à abordagem de Santos e Pereira (1999) sobre ciclo de vida das embalagens, dividindo-o em três etapas: concepção e produção, consumo e pós-consumo. É na terceira que se encontra um conceito pertinente para a temática desta revisão, o de "refunção", que incluiria em sua dimensão o reúso da embalagem pelo usuário para uma função distinta do propósito inicial.

Em segundo lugar, sugere-se que para vislumbrar possibilidades de (re)aproveitamento das embalagens, é necessária uma visão integrativa dos diversificados contextos em que estes artefatos estão inseridos e suas respectivas complexidades, principalmente em relação aos contextos sociais, políticos, culturais e econômicos entremeados na produção, uso e pós-uso das embalagens. De acordo com Gonçalves-dias (2006, p. 466), "dar valor ao objeto em fim de vida significa integrar a idéia de ciclo na fabricação de produtos e suas embalagens. Isto implica que, aos poucos, todos os produtos manufaturados adquiram uma nova função essencial: a de serem valorizáveis. 


\subsubsection{Estudo " $d$ "}

O objetivo fundamental desta dissertação é propor um método de projeto para embalagens que tenha como ponto central questões de sustentabilidade. Para tanto, Pereira (2012) sistematiza e compara alguns dos mais notáveis procedimentos específicos para planejamento de embalagens, e destaca em cada um as principais diretrizes que tratam de conservação ambiental.

O primeiro ponto de contato com a questão central objeto deste artigo ocorre quando a autora analisa as propostas de alguns autores para classificação de embalagens. Destas, destacam-se as taxonomias de Santos Neto (2001) e de Brod Júnior (2004), por incluírem embalagens reutilizáveis na última categoria de suas classificações: "pós-uso" e "pós-descarte", respectivamente.

Em seguida, evidenciam-se as menções aos objetivos e estratégias para projetos de embalagens sustentáveis propostos pela SPC (Sustainable Packaging Coalition), que aponta o "design para reutilização" como uma das estratégias rumo ao objetivo "recuperar recursos".

Pereira (2012) faz um panorama de alguns dos mais notáveis métodos projetuais de design e sinaliza que a partir de 1970, com base nesses procedimentos, começam a surgir métodos específicos para planejamento de embalagens. A autora seleciona oito para uma análise aprofundada, dentre eles o de Bergmiller et al (1976) e o de Seragini (apud NEGRÃO; CAMARGO, 2008), já mencionados neste artigo, e observa que, em geral, enfatizam questões técnicas, funcionais e mercadológicas e não contemplam ou não se aprofundam em questões relacionadas à sustentabilidade. Deste modo, apresenta algumas propostas que têm a conservação ambiental como ponto central, tais como as de Brod Júnior (2004), Sampaio (2008), e o da Sustainable Packaging Coalition, apresentada por meio da obra de Boylston (2009). A partir da revisão teórica e com base na análise comparativa dos métodos mencionados, a autora apresenta uma reclassificação para as embalagens e um método centrado em questões de sustentabilidade.

Quanto a reclassificação, a autora propõe uma taxonomia baseada nas principais fases do ciclo de vida de uma embalagem, em que evidencia-se as duas últimas classificações: a de "uso e descarte", que engloba a postergação no descarte da embalagem quando esta adquire novas funcionalidades mediante apropriações dos usuários; e a de "pós-descarte", que inclui embalagens reutilizáveis, que retornam para a fase de uso.

Em relação ao método desenvolvido, a pesquisadora diz que é fundamentado em uma estrutura centrada no usuário, colaborativa e sistêmica, e o batiza como CICLO, que corresponde às iniciais das cinco etapas projetuais propostas em sua estrutura (Compreender, Idealizar, Configurar, Lapidar e Orientar). As ferramentas foram elaboradas tendo em vista as relações entre os conceitos de sustentabilidade e as lacunas identificadas nos métodos analisados, e foram testados em alguns casos, expostos no trabalho, com o propósito de verificar sua eficácia. Além disso, a autora disponibiliza, no fim do estudo, um documento de referência que sintetiza todas as etapas da proposta, visando facilitar sua aplicação em demais trabalhos.

Embora o reaproveitamento de embalagens seja apenas pontualmente mencionado nesta dissertação e nos métodos estudados pela autora, este trabalho se mostrou de extrema relevância ao reunir e sintetizar os pontos de contato entre diversas obras que tratam do processo projetual de embalagens, principalmente no que diz respeito à sustentabilidade, o que facilitará estudos e reflexões posteriores mais profundas sobre o assunto deste artigo, visando uma resposta objetiva para a indagação desta revisão. 


\subsection{Síntese da revisão}

A análise dos resultados das buscas realizadas nas bases de dados da SciELO, da BDTD e da CAPES, realçam que há poucas pesquisas que abordem diretamente a possibilidade de projetar embalagens de consumo que instiguem o reaproveitamento no ambiente doméstico, principalmente se considerarmos o período relativamente longo estabelecido no protocolo da pesquisa e a considerável demanda por estudos sobre questões de conservação ambiental.

Investigar o projeto de embalagens do ponto de vista da sustentabilidade é o principal ponto de convergência entre os textos analisados. A necessidade de uma abordagem sistêmica e integrativa, bem como o caráter multidisciplinar do planejamento de embalagens, são aspectos bastante enfatizados pelos autores e, portanto, merecem atenção para se pensar em como incorporar perspectivas de reúso no projeto de design de embalagens de consumo.

Embora nenhum dos estudos descritos apresente respostas precisas ou perspectivas mais direcionadas para a questão de pesquisa formulada neste artigo, em todos é possível extrair elementos imprescindíveis para se aprofundar nesta temática, principalmente no que diz respeito a métodos de projeto e as relações e implicações da prática projetual no ambiente, na sociedade e na economia.

\section{Considerações finais}

Tendo em vista a questão formulada neste artigo, "como estimular o reúso de embalagens de consumo no ambiente doméstico, segundo perspectivas de projeto de design?", a Revisão Sistemática da Literatura demonstrou que há a necessidade de se pensar em mais parâmetros para o projeto de embalagens de consumo que visam minimizar seus impactos socioambientais, por meio de alternativas que sejam centradas no usuário e em questões de sustentabilidade, haja vista a inesgotável demanda por soluções para a problemática dos resíduos sólidos urbanos.

Embora a indagação não tenha sido respondida satisfatoriamente, uma vez que nenhum dos textos identificados trata diretamente do reutilização de embalagens de consumo em um sentido propositivo (incluindo orientações de projeto para tal), a pesquisa realizada forneceu algumas diretrizes relevantes para se aprofundar o entendimento das dimensões do reúso relacionadas ao projeto de embalagens, considerando-se que os estudos incluídos na revisão fornecem conceitos, autores e resultados relevantes para futuras abordagens sobre este tema.

Deste modo, além de evidenciar uma lacuna que poderá nortear novos estudos sobre o assunto, verificou-se a necessidade de realizar buscas em outras bases de dados e com outros "strings de busca", para que o cenário se amplie e, eventualmente sejam identificados novos subsídios para o mestrado em curso.

\section{Referências}

ASSOCIAÇÃO BRASILEIRA DE EMPRESAS DE LIMPEZA PÚBLICA E RESÍDUOS ESPECIAIS (ABRELPE). Panorama dos Resíduos Sólidos no Brasil 2017. Disponível em: <http://abrelpe.org.br/ panorama/2017>. Acesso em: 22 mar. 2019.

BERGMILLER, K. H. et al (Coord.) Manual para planejamento de embalagens. Rio de Janeiro: MIC - STI/IDI/MAM - RJ, 1976.

BOYLSTON, S. Designing Sustainable Packaging. Londres: Laurence King, 2009.

BROD JR., M. Desenho de embalagem: projeto mediado por parâmetros ecológicos. Dissertação (Mestrado) - Universidade Federal de Santa Maria, Santa Maria, 2004. 
$\mathrm{BUCCl}, \mathrm{D}$. Z. Processo de desenvolvimento de produto-embalagem: uma proposta orientada à sustentabilidade. Tese (Doutorado) - Centro Tecnológico, Universidade Federal de Santa Catarina, Florianópolis, 2010.

CAPELINI, M. Potencialidade e aplicação da prevenção de resíduos de embalagens: abordagem sobre o projeto do produto e o consumo. 2007. Tese (Doutorado) - Escola de Engenharia de São Carlos, Universidade de São Paulo, São Carlos, 2007.

COLLINS DICTIONARY. Word of the Year 2018. Disponível em: <https://www.collinsdictionary .com/woty>. Acesso em: 22 mar. 2019.

FISHER, T.; SHIPTON, J. Designing for re-use: the life of consumer packaging. Londres: Earthscan, 2010.

GOMES, D. D. T. C. O r em design: a reutilização aplicada ao design. 2011. Dissertação (Mestrado) Faculdade de Engenharia, Universidade do Porto, 2011.

GONCALVES-DIAS, S. L. F. Há vida após a morte: um (re)pensar estratégico para o fim da vida das embalagens. Gestão \& Produção, São Carlos, v. 13, n. 3, p. 463-474, Dez. 2006.

HIGGINS J.P.T.; GREEN S. (Eds.) Cochrane Handbook for Systematic Reviews of Interventions. 5.1.0, 2011. Disponível em: <http://www.handbook.cochrane.org>. Acesso em: 26 mar. 2019.

JEDLIČKA, W. Packaging sustainability: tools, systems, and strategies for innovative package design. Nova Jérsia: John Wiley \& Sons, 2009.

MANZINI, E.; VEZZOLI, C. O desenvolvimento de produtos sustentáveis: os requisitos ambientais dos produtos industriais. São Paulo: Edusp, 2002.

MINISTÉRIO DO MEIO AMBIENTE. Impacto das embalagens no meio ambiente. Disponível em: <http://www.mma.gov.br/responsabilidade-socioambiental/producao-e-consumosustentavel/consumo-consciente-de-embalagem/impacto-das-embalagens-no-meio-ambiente.html>. Acesso em: 6 abr. 2019.

NEGRÃO, C.; CAMARGO, E. P. Design de embalagem: do marketing à produção. São Paulo: Novatec, 2008.

OBREGON, R. F A. (Org.) Perspectivas de pesquisa em design: estudos com base na Revisão Sistemática de Literatura. Erechim: Deviant, 2017.

PEREIRA, P. Z. Proposição de metodologia para o design de embalagem orientada à sustentabilidade. Dissertação (Mestrado) - Escola de Engenharia, Universidade Federal do Rio Grande do Sul, Porto Alegre, 2012.

SAMPAIO, C. P. Diretrizes para o design de embalagens em papelão ondulado movimentadas entre empresas com base em sistemas produto-serviço. Dissertação (Mestrado) - Setor de Ciências Humanas, Letras e Artes, Universidade Federal do Paraná, Curitiba, 2008.

SANTOS NETO, L. A. Metodologias de desenvolvimento de embalagem: proposta de aprimoramento para ensino de projeto gráfico. Dissertação (Mestrado) - Universidade Federal de Santa Maria, Santa Maria, 2001.

SANTOS, M. C. L.; PEREIRA, A. F. Packaging: function, re-function and malfunction: from consumer society to the homeless material culture. In: ECODESIGN'99, Fev. 1999. Anais... Tóquio, fev. 1999, p. 492-496.

SHEDROFF, N. Design is the problem: the future of design must be sustainable. Nova lórque: Rosenfeld Media, 2009.

SOUSA, C. S. M. Impacto ambiental: parâmetro para projeto de embalagens, o caso do plástico. 2000. Tese (Doutorado) - Faculdade de Arquitetura e Urbanismo, Universidade de São Paulo, São Paulo, 2000. 